Check for updates

Cite this: RSC Adv., 2018, 8, 5500

Received 3rd December 2017 Accepted 27th January 2018

DOI: 10.1039/c7ra13001e

rsc.li/rsc-advances

\section{Nanospace-confined preparation of uniform nitrogen-doped graphene quantum dots for highly selective fluorescence dual-function determination of $\mathrm{Fe}^{3+}$ and ascorbic acid $\uparrow$}

\begin{abstract}
Hongbo Xu, Shenghai Zhou, (D) * Jinyu Liu and Yajun Wei
$\mathrm{N}$-Doped graphene quantum dots (N-GQDs) combine the advantages of $\mathrm{N}$-doped carbon and quantum dot materials, displaying enhanced performance in electrocatalysis, drug delivery, sensing and so on. In this work, novel hydrotropic N-GQDs with controlled size are obtained for the first time via a nanospace-confined preparation strategy, in which $\mathrm{HNO}_{3}$ vapour serves as scissors for quickly cutting the $\mathrm{N}$-doped carbon nanolayer in the confined nanospace of reusable mesoporous molecular sieves. The as-prepared N-GQDs exhibit a uniform lateral size of about $2.4 \mathrm{~nm}$, high photostability and yellow fluorescence, which is strongly quenched upon addition of ferric ions due to the coordination between ferric ions and N/O-rich groups of the N-GQDs surface. Significantly, the fluorescence response to $\mathrm{Fe}^{3+}$ is linear in the 0.5 to $40 \mu \mathrm{M}$ concentration range and the N-GQDs showed good selectivity and satisfying recovery for ferric ion detection in tap water. Noteworthily, the quenched fluorescence by $\mathrm{Fe}^{3+}$ can be recovered by adding ascorbic acid (AA), which efficiently destroyed the coordination between $\mathrm{Fe}^{3+}$ and $\mathrm{N}-$ GQDs. Based on this principle, the N-GQDs were used to successfully construct an AA sensor, exhibiting a wide linearity range (between 0.5 and $90 \mu \mathrm{M}$ ) with a low detection of limit ( $80 \mathrm{nM}$ at $\mathrm{S} / \mathrm{N}=$ 3) and better selectivity towards AA compared with other common physiological substances. Finally, the constructed fluorescence sensor was employed successfully for AA determination in fish blood with satisfactory recovery ranging from 95.3 to $106.2 \%$. The results indicate that N-GQDs synthesized by the nanospace-confined strategy are promising in biosensor fabrication.
\end{abstract}

\section{Introduction}

Graphene quantum dots (GQDs) are a new kind of thin carbon quantum dot material. The lateral size of a graphene sheet is less than $100 \mathrm{~nm} .^{1}$ The unique structure and composition of GQDs endows them with favourable properties including low toxicity, good biocompatibility, large surface area and high photostability. ${ }^{2}$ As a result, GQDs have become an important material for various applications such as anticancer therapy, biomedical imaging, environmental monitoring, photovoltaic and light-emitting devices, etc. ${ }^{3-6}$ To further expand the application field of GQDs, a powerful method is to fabricate

College of Chemistry and Chemical Engineering, Hebei Normal University for Nationalities, Chengde 067000, China. E-mail: zhoush10@mails.jlu.edu.cn; Tel: +86-314-2370567

$\dagger$ Electronic supplementary information (ESI) available: UV-vis absorption spectrum of the N-GQDs dispersed in water and photograph of the N-GQDs solutions taken under illumination of UV light (Fig. S1a); fluorescence emission spectra of the N-GQDs aqueous solution at different excitation wavelengths from 300 to $400 \mathrm{~nm}$ (Fig. S1b); determination of $\mathrm{Fe}^{3+}$ in tap water samples (Table S1); determination of AA in fish blood samples (Table S2). See DOI: 10.1039/c7ra13001e heteroatom-doped GQDs through doping heteroatoms into the carbon skeleton with the aim of altering the electronic characteristics of GQDs. ${ }^{7,8}$ Recently, some significant work demonstrated successful preparation of $\mathrm{N}$-doped graphene quantum dots (N-GQDs) with enhanced performances for some given applications. ${ }^{9,10}$ For instance, Qu's group demonstrated the optoelectronic properties of GQDs were greatly altered by nitrogen incorporation. ${ }^{9}$ The N-GQDs prepared by an electrochemical synthesis method in their study exhibited an enhanced electrocatalytic performance for the oxygen reduction reaction compared with $\mathrm{N}$-free counterparts. In another study, Chen's group reported an efficient fluorescent N-GQD probe for low-cost, simple and selective determination of ferric ions $\left(\mathrm{Fe}^{3+}\right)$ in lake water samples. ${ }^{10}$ They found that the in-plane doping of the carbon skeleton with nitrogen promoted the coordination between GQDs and ferric ions, thus leading to success in the fluorescence determination of ferric ions.

Currently, the N-GQDs are prepared by two main methods, including "bottom-up" and "top-down" routes. ${ }^{11,12}$ The bottomup approach refers to growing small molecular precursors to big N-GQDs by utilizing the high-pressure and high-temperature method, thermal pyrolysis, stepwise organic synthesis, 
etc. ${ }^{\mathbf{6}, 13,14}$ Although these methods can produce successfully $\mathrm{N}$ GQDs with well-defined sizes and shapes, this strategy is still in its infancy and has limitations to overcome such as low water solubility, strong aggregation between N-GQDs, complex synthetic procedure and special organic precursor. ${ }^{6}$ The topdown approach are the cleavage of bulk carbon materials into nanosized N-GQDs via acidic oxidation, electrochemical exfoliation, hydrothermal/solvothermal treatment, and so on. ${ }^{\mathbf{8 , 9 , 1 5 , 1 6}}$ Compared with the bottom-up strategy, this method shows outstanding advantages like simple operation, abundant precursors, high water solubility, and easy surface functionalization for N-GQDs. ${ }^{6}$ However, the faults of time-consuming cutting process, relatively expensive cutting devices, sophisticated separation process, and the difficulty in size-controlled production caused by non-selective "top-down" cutting are non-negligible. ${ }^{17}$ Therefore, it is significant to prepare the $\mathrm{N}$ GQDs with controlled size and good water-solubility via a topdown route that has the facile and fast separation process as well as low cost.

Lately, the researchers have introduced the concept of nanoreactor to synthesize pristine GQDs in the confined nanospace of inorganic nanostructure materials. This ideal nanospace-confined synthesis strategy provides GQDs with controllable layer number and uniform lateral size. ${ }^{18,19}$ For instance, Lu's group synthesized the single-layered GQDs via hydrothermal carbonization of citrate guests in twodimensional (2D) confined interlayer space of layered double hydroxides (LDHs) hosts. ${ }^{18}$ The success in the layer-controlled GQDs production is attributed to an obvious 2D nanospace confinement effect. Their work provides a real possibility to understand the intrinsic connection between the structure and property of GQDs, due to the controllable synthesis of GQDs. Besides, in our previous work, the size-controlled GQDs were obtained via using a $\mathrm{HNO}_{3}$ vapour as the acidic scissor to cleave the carbon nanolayer in the pore channel of mesoporous carbon/silica nanocomposite. ${ }^{19}$ The nanoscale pore of the carbon/silica material effectively limits the size of graphene quantum dots. More importantly, this nanoreactor-confined preparation for GQDs via top-down route not only endowed GQDs with good dispersibility, but also avoided timeconsuming separation and purification processes. Inspired by the nanospace-confined synthesis strategy, the heteroatomdoped GQDs with controlled size and water-solubility may be obtained by using an appropriate nanoreactor and precursor. However, to the best of our knowledge, the controlled-synthesis of N-GQDs is not achieved via the above mentioned nanospaceconfined synthesis strategy up to now. So, one of the purposes of the work is to develop a low-cost top-down method for the nanospace-confined preparation of N-GQDs with good watersolubility and controlled size.

Ferric ion, an inorganic metal ion, plays crucial role in the physiology of humans. Its abnormal amount will cause some serious diseases. For example, $\mathrm{Fe}^{3+}$ deficiency can result in anemia while $\mathrm{Fe}^{3+}$ with excess concentration in blood will cause kidney damage and hemochromatosis. ${ }^{20}$ On the other hand, as an important antioxidant in biological systems, ascorbic acid (AA) functions in some important biochemical reaction. For instance, AA can quickly react with free-radicals and thus effectively decrease free-radical damage that usually results in some serious diseases like Parkinson's disease and cancer. ${ }^{21}$ Hence, it is very essential to establish accurate and simple methods for the rapid determination of $\mathrm{Fe}^{3+}$ and AA. So far, various analytical methods for $\mathrm{Fe}^{3+}$ or $\mathrm{AA}$ have been reported, including fluorescence approach, ${ }^{22,23}$ colorimetric determination, ${ }^{24,25}$ electrochemical method ${ }^{26,27}$ and liquid chromatography, ${ }^{28}$ etc. Among the reported methods, fluorescent method provides obvious merits compared with other methods, because of its simplicity, convenience and sensitivity. ${ }^{29}$ As a result, various fluorescent sensing probes such as organic dyes, semiconductor quantum dots, metal nanoclusters, are utilized to selectively and sensitively determine ferric iron and AA. Compared with above mentioned fluorescent probes, graphene quantum dot has recently won more attention as a novel probe in analyte detection based on the following three obvious merits. ${ }^{11,22}$ Firstly, the accuracy and repeatability of determination results is ensured due to their excellent photostability. Secondly, the detection safety was guaranteed in view of their low toxicity and good biocompatibility. Thirdly, their good water-dispersibility also makes GQDs more feasible for real sample analysis. ${ }^{22}$ As a result, graphene quantum dots have a great potential in the sensitive determination of either $\mathrm{Fe}^{3+}$ or AA. However, the sensing applications of GQDs, especially $\mathrm{N}$ GQDs, are still in their infancy. And very little work has been done for the dual-analyte determination of both $\mathrm{Fe}^{3+}$ and $\mathrm{AA}$, especially using the N-GQDs with controlled size, good waterdispersibility and low-cost.

Herein, the nanospace-confined preparation of N-GQDs with controlled size was achieved for the first time via cutting $\mathrm{N}$ containing carbon nanolayer with $\mathrm{HNO}_{3}$ vapour in the confined pore channel of renewable mesoporous silica molecular sieves. The as-prepared N-GQDs exhibit a uniform size, excellent water solubility and yellow fluorescence. Significantly, the fluorescence of N-GQDs is strongly and selectively quenched by ferric ion compared with environmentally relevant metal ions including $\mathrm{Pb}^{2+}, \mathrm{Al}^{3+}, \mathrm{Hg}^{2+}, \mathrm{Cu}^{2+}, \mathrm{Ni}^{2+}, \mathrm{Co}^{2+}, \mathrm{Na}^{+}, \mathrm{K}^{+}, \mathrm{Fe}^{2+}$, $\mathrm{Cd}^{2+}, \mathrm{Ag}^{+}, \mathrm{Mn}^{2+}$ and $\mathrm{Zn}^{2+}$, which may be due to the formation of the N-GQDs- $\mathrm{Fe}^{3+}$ coordination complex. Subsequently, the fluorescence of N-GQDs-Fe ${ }^{3+}$ system is selectively recovered via the addition of AA and increases linearly with its concentration. Based on the change of fluorescence signal, a sensitive and feasible analytical method is developed for the selective determination of both $\mathrm{Fe}^{3+}$ and $\mathrm{AA}$ in real samples with satisfactory results.

\section{Experimental section}

\subsection{Chemicals and instrumentation}

In this work, all purchased reagents did not be further purified for experimental use. And, all the aqueous solutions were finished with ultrapure water before experiments. The morphology and microstructure of the materials were wellcharacterized by scanning electron microscopy (SEM, JEOL JSM 6700-F, Japan), X-ray diffraction (XRD, Siemens D5005, Germany), atomic force microscopic (AFM, Bruker, Multimode 
8, America), transmission electron microscopy (TEM, JEOL, JEM-3010, Japan), Fourier transform infrared spectra (FT-IR, Nicolet Magna 5PC, America) X-ray photoelectron spectroscopy (XPS, Thermo Fisher Scientific, America), Raman spectra (Renishaw, inVia, England) and nitrogen adsorption (BEL, Sorpmax, Japan). The optical property of N-GQDs was investigated by UV-vis spectra (Shimadzu, UV-1800, Japan) and fluorescence spectra (Hitachi, F-7000, and Japan).

\subsection{Preparation of mesoporous silica molecular sieve (SBA-} 15)

The mesoporous silica molecular sieve template was prepared according to a reported method. ${ }^{30}$ Briefly, $4 \mathrm{~g}$ surfactant (P123: $\left.\mathrm{EO}_{20} \mathrm{PO}_{70} \mathrm{EO}_{20}\right), 105 \mathrm{ml}$ water, $20 \mathrm{ml}$ hydrochloric acid (37\%) and $8.5 \mathrm{~g}$ tetraethoxysilane were mixed to form a homogeneous solution. Subsequently, the homogeneous solution was heated in an autoclave at $110{ }^{\circ} \mathrm{C}$ for $24 \mathrm{~h}$. The precipitates in the autoclave were filtered and cleaned with water and ethanol sequentially. And then the product was heated for the removal of P123 surfactant at $550{ }^{\circ} \mathrm{C}$ for $6 \mathrm{~h}$. Finally, the white SBA-15 material with opened pore was obtained.

\subsection{Synthesis of mesoporous nitrogen/carbon/silica composite (N/C/SBA-15)}

A key in the nanospace-confined preparation of N-GQDs is how to prepare ordered mesoporous N/C/SBA-15 composite containing both confined nanopore channel and N-doped graphene layer on the pore wall. Some significant works demonstrated the cladding of carbon layers on the pore wall of mesoporous silica molecular sieve resulted in the formation of carbon nanotube $^{31}$ and mesoporous carbon with tube arrays. ${ }^{32}$ Inspired by those, the synthesis of N/C/SBA-15 composite with graphene layers and retained pore was achieved by the following processes, as shown in Fig. 1A. Briefly, sulphuric acid, pyrrole, ethanol and trimethylbenzene were stirred for the formation of a homogeneous solution in which the sulphuric acid and pyrrole were used as a catalyst and carbon nitrogen source, respectively. The calcined SBA-15 was then impregnated with the above solution at room temperature. The mixture was heated at $80{ }^{\circ} \mathrm{C}$ and then $160{ }^{\circ} \mathrm{C}$ each for 6 hours. Lastly, the resulting composite was carbonized at $800{ }^{\circ} \mathrm{C}$ for $2 \mathrm{~h}$ in nitrogen atmosphere, resulting in the formation of ordered mesoporous N/C/SBA-15 material.

\subsection{Nanospace-confined synthesis of N-GQDS}

Herein, the size-controlled N-GQDs were prepared by selecting the mesoporous N/C/SBA-15 with graphene layer as raw materials via a facile and low-cost steaming procedure. As shown in Fig. 1B, $0.15 \mathrm{~g}$ of N/C/SBA-15 power was added into a selfdesigned glass steamer with a porous $\mathrm{SiO}_{2}$ griddle in its middle. And then $2 \mathrm{ml}$ liquid concentrated $\mathrm{HNO}_{3}$ were added into an autoclave, aiming at creating the acid vapour scissors. Subsequently, the glass steamer was transferred to above autoclave and heated for $\mathrm{HNO}_{3}$ vapour cleaving at $150{ }^{\circ} \mathrm{C}$ for $3 \mathrm{~h}$. After reaction, the steamer was moved into a clean beaker and filtered via ultrapure water. Due to the confined effect of

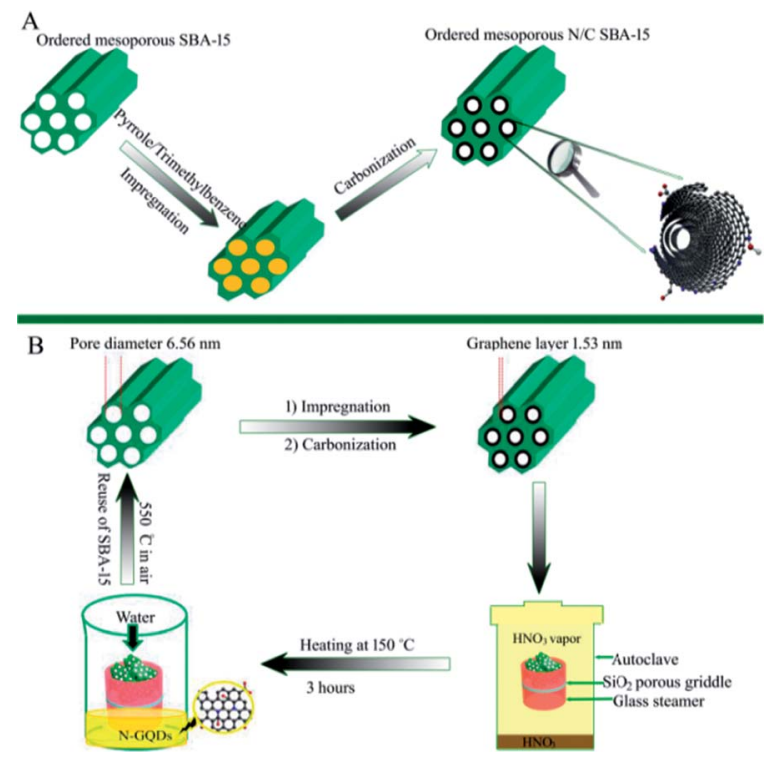

Fig. 1 (A) A schematic diagram of the synthesis of ordered mesoporous N/C/SBA-15 and a visual illustration of the nano/microstructure of carbon nanolayer. (B) Schematic diagram of the synthesis of N-GQDs.

nanosized pore in N/C/SBA-15 and the in situ filtration of porous $\mathrm{SiO}_{2}$ griddle, the N-GQDs with controlled size dispersed well in the above filtrate that was defined as N-GQDs solution. After the filtration via glass steamer, residual N/C/SBA-15 composite was transferred to a ceramic crucible and then calcined at $550{ }^{\circ} \mathrm{C}$ for the rebirth of the mesoporous silica template. The SBA-15 template possesses still highly ordered mesoporous structure after six cycles, which was demonstrated by the following results and discussions, providing a low-cost in nanospace-confined preparation. And the N-GQDs can be easily separated from liquid concentrated $\mathrm{HNO}_{3}$ via the self-designed glass steamer, avoiding the tedious separation process compared to traditional solution routes. In addition, the vapour cutting approach only required about $2 \mathrm{ml} \mathrm{HNO}_{3}$ for the N-GQDs preparation, reducing the acid consumption. And the liquid $\mathrm{HNO}_{3}$ in autoclave can be recyclable use because it only provides $\mathrm{HNO}_{3}$ vapour in the N-GQDs preparation process, which makes the current vapour cutting method relatively eco-friendly.

\section{Results and discussions}

\subsection{Structure characterization of mesoporous SBA-15 template and N/C/SBA-15 composite}

3.1.1 Small-angle XRD characterization. The pore structural order of mesoporous SBA-15 template and N/C/SBA-15 composite were investigated by small-angle XRD (see Fig. 2). The small-angle XRD pattern of calcined SBA-15 material (Fig. 2A) displays three obvious peaks assigned to (100), (110) and (200) diffractions of 2D hexagonal $p 6 \mathrm{~mm}$ symmetry of the ordered pore system. ${ }^{33}$ Significantly, small-angle XRD of the N/ C/SBA-15 composite (Fig. 2B) exhibits three well-resolved reflection peaks at similar locations, confirming the ordered 

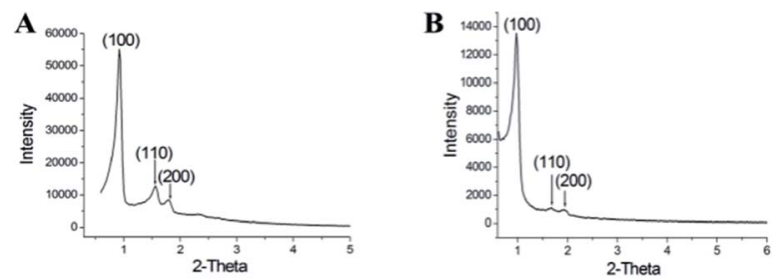

C
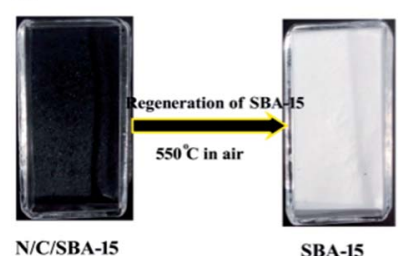

D

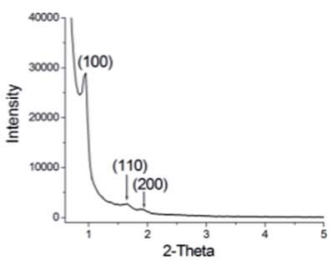

Fig. 2 Small-angle XRD patterns of ordered mesoporous materials: (A) original SBA-15, (B) N/C/SBA-15, (D) the regenerated SBA-15. (C) Regeneration of SBA-15 template via the calcination in air.

mesopore of the silica template was reserved after the inclusion of N-doped graphene layers. Noteworthily, the three characteristic peaks of the as-prepared N/C/SBA-15 became weakened due to the graphene cladding and the altered scattering behavior. ${ }^{32}$ Furthermore, revitalization of the parent silica template is very important to reduce the production cost of $\mathrm{N}$ GQDs. As shown in Fig. 2C, grey N/C/SBA-15 after reaction was calcinated to remove the unreacted carbon and generate the white SBA-15 powder. After 6 cycles, XRD pattern of the regenerated SBA-15 shows still the three well-resolved diffraction peaks in the small-angle range of $2 \theta=0.6-6.0$ (see Fig. 2D), indicating the mesoporous silica is renewable because of its high chemical and heat stability.

3.1.2 Nitrogen adsorption characterization. Pore features of the silica template and its corresponding composite were further determined by $\mathrm{N}_{2}$ adsorption-desorption at $77 \mathrm{~K}$. Both SBA-15 template (Fig. 3A) and N/C/SBA-15 composite (Fig. 3B) display type IV adsorption isotherms and obvious hysteresis
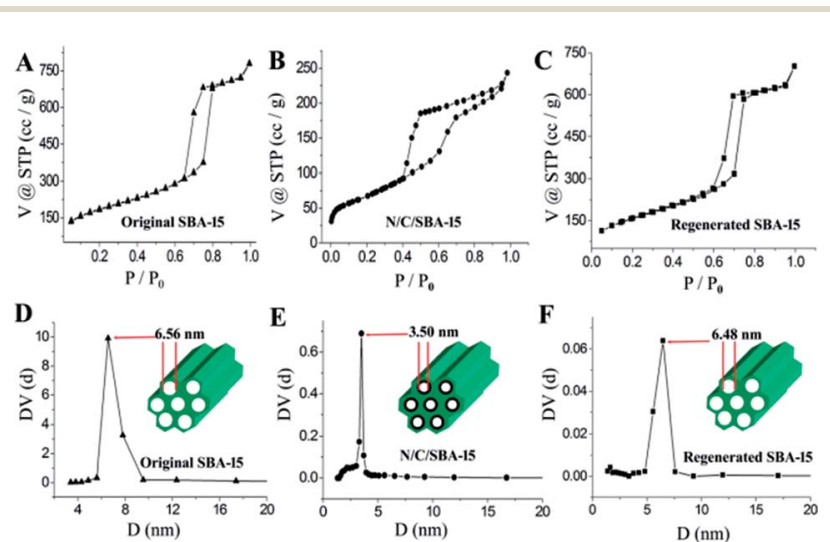

Fig. $3 \mathrm{~N}_{2}$ adsorption-desorption isotherms of ordered mesoporous materials: (A) original SBA-15, (B) N/C/SBA-15 and (C) regenerated SBA-15. Pore size distribution of mesoporous materials. From (D) to (F), the material is original SBA-15, N/C/SBA-15 and regenerated SBA-15, respectively. loops, suggesting the presence of mesopores. The adsorption results support their low-angle XRD characterization data displayed in Fig. 2. Furthermore, a hysteresis loop appearing at $P /$ $P_{0}=0.4-0.6$ for the $\mathrm{N} / \mathrm{C} / \mathrm{SBA}-15$ was observed, which is lower than that of the parent SBA-15 template $\left(P / P_{0}=0.6-0.8\right)$, suggesting the N/C/SBA-15 composite possesses a smaller mesopore size due to the cladding of $\mathrm{N}$-doped graphene on the inner surface of SBA-15. ${ }^{32}$ This speculation is underlined by the poresize distribution, which is calculated based on their respective desorption curve with the Barrett-Joyner-Halenda method. As shown in Fig. 3D, the original SBA-15 template has relatively large mesopores at an average size of $c a .6 .56 \mathrm{~nm}$, while the N/C/ SBA-15 (Fig. 3E) exhibits a smaller mesopore size of $c a .3 .50 \mathrm{~nm}$. From above these two pore sizes, the thickness of $\mathrm{N}$-doped graphene layer was calculated to be $c a .1 .53 \mathrm{~nm}$. These $\mathrm{N}$ doped graphene sheets on inner wall and retained mesopores of the nitrogen/carbon/silica composite would present a great opportunity to prepare the size-controlled N-GQDs via top-down route in the confined mesoporous space. Besides, the mesostructure stability of the SBA-15 template after 6 cycles was investigated by nitrogen adsorption. As shown in Fig. 3C, the adsorption isotherm of regenerated SBA-15 is of type IV and high similarity to original SBA-15. Moreover, its averaged pore size is about $6.48 \mathrm{~nm}$ (Fig. 3F), indicating that the SBA-15 template possesses high mesostructure stability and can be reused at least six times.

3.1.3 Scanning electron microscopy and transmission electron microscopy characterizations. As shown in SEM image of Fig. 4A, the as-synthesized SBA-15 exhibits uniform nanorod morphologies. The mesoporous N/C/SBA-15 material (Fig. 4B) shows the same morphology as template SBA-15, suggesting a well macroscopic and mesoscopic impregnation for carbon loading. From the TEM images displayed in Fig. 4D and E, the regular stripe-like arrangement pore structure was observed in both SBA-15 template (Fig. 4D) and N/C/SBA-15 composite (Fig. 4E) material, which is in accord with their small-angle XRD and nitrogen adsorption data. Meanwhile, the discovery of nanopore arrays in N/C/SBA-15 indicated the successful nanocasting of $\mathrm{N}$-doped carbon nanotubes in the inner channels of the SBA-15. These preserved open porous structures provide

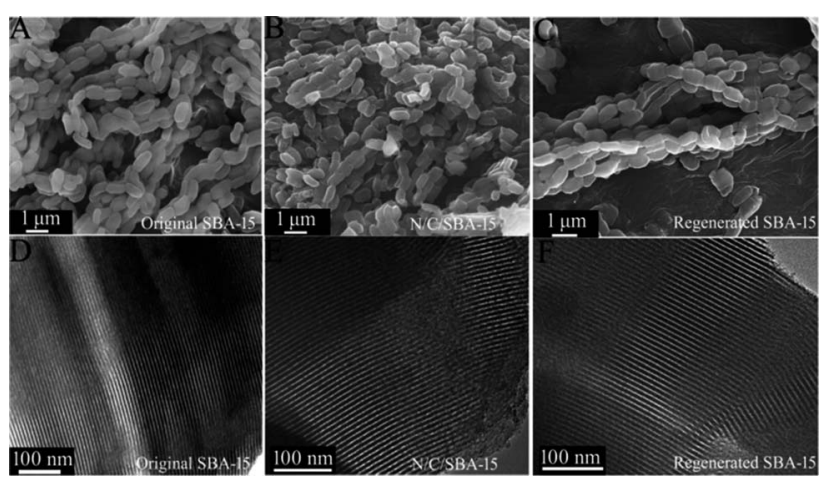

Fig. 4 SEM (A) and TEM (D) images of original SBA-15, SEM (B) and TEM (E) images of N/C/SBA-15, SEM (C) and TEM (F) images of regenerated SBA-15. 
a huge reaction interface and cutting point to react with $\mathrm{HNO}_{3}$ vapour. More importantly, these small-sized pores provide a confined space and result in the formation of the N-GQDs with controlled size.

Reusability and recyclability of the mesoporous SBA-15 template are very important for the environment-friendly and low-cost preparation of N-GQDs. Besides above small-angle XRD and $\mathrm{N}_{2}$-adsorption characterizations for the regenerated SBA15, scanning electron microscopy and transmission electron microscopy also were used for the structure investigation of regenerated SBA-15. From the SEM (Fig. 4C) and TEM (Fig. 4F) images, the regenerated SBA-15 still displays a rodlike morphology and an ordered mesopore arrangement, which agree very well with its small-angle XRD and adsorption result. And no distinguishable structural difference between original SBA-15 and generated SBA-15 demonstrate an exceptional recyclability of the parent SBA-15 template, thus endowing the unique top-down synthesis with low-cost and environmentally friendly.

\subsection{Characterization of N-GQDs}

3.2.1 TEM and AFM characterizations. TEM image of the $\mathrm{N}$ GQDs was displayed in Fig. 5A. In terms of its image, the NGQDs are well dispersed owing to the inherent merit of topdown cleaving strategy. All these N-GQDs based on nanospace-confined strategy show promising narrow lateral size distribution from 1.6 to $3.5 \mathrm{~nm}$, attributing to the cleavage of N-doped graphene layer in the tiny mesopore space (see the Fig. 5B). In detail, average particle size of the N-GQDs is about $2.4 \mathrm{~nm}$ calculated based on about 100 random quantum dots. The representative high resolution TEM images (inset in Fig. 5A) suggest that N-GQDs possess relatively good crystallinity. Their lattice fringes were calculated at about $0.214 \mathrm{~nm}$ for N-GQDs, which could be ascribed to (100) lattice fringes of graphene. ${ }^{34}$ On the other hand, heights of the obtained N-GQDs were investigated by atomic force microscopic via placing the

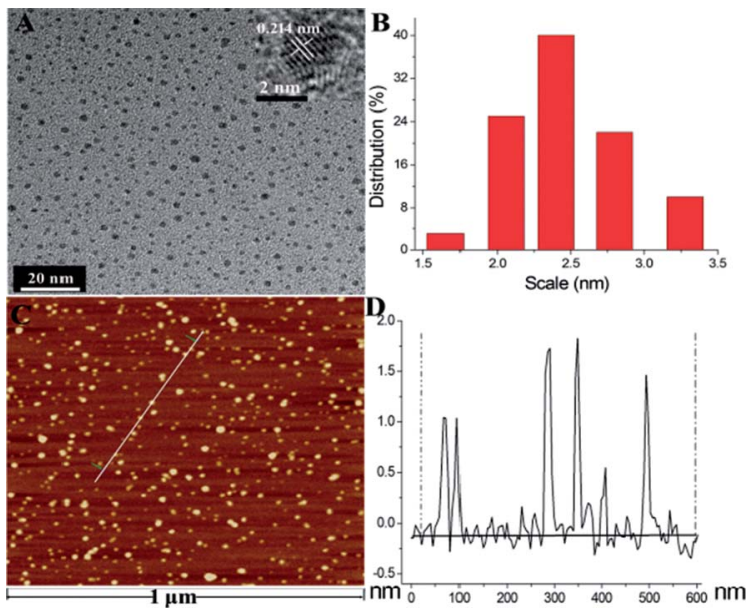

Fig. 5 (A) TEM image of N-GQDs. Inset: high resolution TEM image of a typical N-GQD. (B) The size distribution of N-GQDs. AFM image (C) and height profile (D) of N-GQDs. quantum dots onto the micas. The typical AFM image was displayed in the Fig. 5C and shows a good dispersibility of N-GQDs again. Their corresponding heights were between 0.5 and $2 \mathrm{~nm}$ (Fig. 5D), suggesting that the as-prepared N-GQD consists of 1-3 graphene layers. ${ }^{35}$

3.2.2 Characterizations of the FT-IR, XPS, XRD and Raman spectroscopy. Besides the particle size, the surface state of GQDs is also recently found to be an important influence factor for tuning fluorescence, catalytic activity and even sensing property. ${ }^{\mathbf{1 4 3 6}}$ So the N-GQDs surface state was confirmed by FT-IR and XPS spectroscopy in this work. The FT-IR result of N-GQDs was shown in the Fig. 6A. The band at $1041 \mathrm{~cm}^{-1}$ is corresponded to $\mathrm{C}-\mathrm{N}$ bond, indicating an effective doping of nitrogen atom. ${ }^{15}$ And the three peaks at 1390, 1625 and $1724 \mathrm{~cm}^{-1}$ demonstrate the existence of $\mathrm{C}-\mathrm{OH}, \mathrm{C}=\mathrm{C}$ and $\mathrm{C}=\mathrm{O}$ in N-GQDs, respectively. ${ }^{37}$ The band at $3420 \mathrm{~cm}^{-1}$ is ascribed to the $\mathrm{O}-\mathrm{H}$ bond, suggesting the presence of lots of hydroxyl groups on the N-GQDs surface. ${ }^{37}$ These O-rich groups lead to favourably hydrophilic property. And, their surface composition and elements were further confirmed by XPS characterization. Its full scan XPS spectrum (Fig. 6B) exhibits C1s (284 eV), N1s (401 eV) and O1s $(532 \mathrm{eV})$ peak, indicating that nitrogen doping was effectively accomplished by top-down cutting method for graphene quantum dots. ${ }^{9}$ In detail, the nitrogen contents of N-GQDS are $c a$. 5.3 at\% that approaches the previously published value. ${ }^{12}$ Also, C1s peak of N-GQDs (Fig. 6C) showed the six deconvoluted bands at $284.2 \mathrm{eV}, 284.7 \mathrm{eV}, 285.2 \mathrm{eV}, 286.3 \mathrm{eV}$, $288.4 \mathrm{eV}, 288.9 \mathrm{eV}$, which can be attributed to $\mathrm{C}=\mathrm{C}, \mathrm{C}-\mathrm{C}$, $\mathrm{C}-\mathrm{N}, \mathrm{C}-\mathrm{O}, \mathrm{C}=\mathrm{O}, \mathrm{O}-\mathrm{C}=\mathrm{O}$ characteristic peak, respectively. ${ }^{15}$ This assignment is well consistent with its the FT-IR result. Furthermore, N1s spectrum of the N-GQDs (Fig. 6D) exhibits the existence of $\mathrm{N}$-containing groups like graphitic-N $(\sim 401.7$ $\mathrm{eV})$ and pyrrolic-N $(\sim 401 \mathrm{eV}) .{ }^{9,38}$ The nitrogen/oxygen groups on the N-GQDs surface will also benefit a chelation of the $\mathrm{N}-$ GQDs with metal ions in aqueous solution, leading to the promising applications like fluorescence sensing of metallic ions, as discussed in the later part.

The structure of as-prepared N-GQDs was further investigated via X-ray diffraction and Raman spectroscopy. As shown in Fig. 6E, XRD pattern of the as-prepared N-GQDs displays a broad (002) diffraction band at $23.6^{\circ}$ corresponded to a bilayer or few-layer graphene structure. The corresponding interlayer spacing is about $0.377 \mathrm{~nm}$, which is $0.037 \mathrm{~nm}$ larger in comparison with $0.34 \mathrm{~nm}$ of graphite because of the existence of N/O-richgroups. ${ }^{39}$ Furthermore, the Raman spectrum of the N-GQDs (Fig. 6F) exhibits two obvious characteristic bands of carbon materials, namely $\mathrm{G}$ band at $1590 \mathrm{~cm}^{-1}$ and $\mathrm{D}$ band at $1359 \mathrm{~cm}^{-1}$, respectively. ${ }^{16}$ On the other hand, the intensity ratio $I_{\mathrm{D}} / I_{\mathrm{G}}$ of 0.92 suggested the formation of defects and a concomitant introduction of nitrogen into in-plane of graphene. ${ }^{\mathbf{1 6}}$ These investigations combined with FT-IR and XPS results indicated N-GQDS containing rich nitrogen/oxygen groups were successfully accomplished by this developed nanospace-confined strategy. 

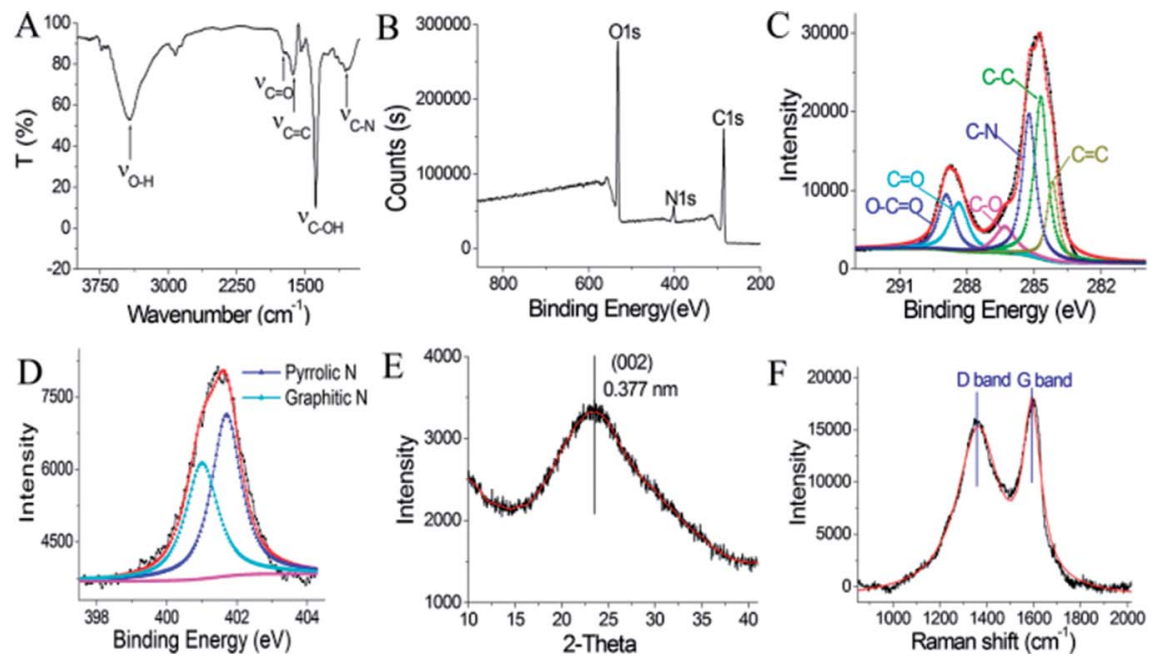

Fig. 6 FT-IR spectrum (A) and XPS survey scan (B) of N-GQDs. C1s (C) and N1s (D) XPS spectra of the N-GQDs. XRD (E) and Raman spectra (F) of N-GQDs.

\subsection{Optical properties of the N-GQDS}

3.3.1 UV-vis absorption and fluorescent property. To further explore the optical properties of the N-GQDs, UV-vis absorption and fluorescence spectroscopic characterizations were accomplished and displayed in Fig. S1. $\dagger$ As seen in Fig. S1A, $\dagger$ a broad absorption between 717 and $200 \mathrm{~nm}$ was well observed in the absorption spectrum of N-GQDs. The broad absorption of N-GQD may make it have the potential application in optoelectronic devices, as suggested by Gupta et al. ${ }^{40}$ Also a clear absorption peak at about $210 \mathrm{~nm}$ was observed and ascribed to the $\pi \rightarrow \pi^{*}$ transition of aromatic sp $^{2}$ domains. ${ }^{38}$ The inset of Fig. S1A $\uparrow$ shows the optical images of the N-GQDs under UV light at wavelengths of $365 \mathrm{~nm}$. Significantly, N-GQDs exhibited a yellow fluorescence. To further explore its fluorescent property, the fluorescence spectra excited at different wavelengths varying from 300 to $400 \mathrm{~nm}$ were collected and exhibited in Fig. S1B. $\dagger$ It is noticed that the emission peaks of the obtained N-GQDs remain almost at similar positions when the excitation wavelengths increase gradually. This result indicates the as-prepared N-GQDs have a nearly excitationindependent behavior. ${ }^{1}$ Furthermore, the fluorescence intensity of the N-GQDs altered with the variation of excitation wavelengths, showing a strongest fluorescence at $340 \mathrm{~nm}$. So, the excitation wavelength of $340 \mathrm{~nm}$ was employed for the following study.

3.3.2 Determination of ferric ion. Besides the electric applications of N-GQDs, one of promising optical applications of GQDs is as fluorescence probe for determination of some metal ions ${ }^{5}$ owing to the merits of good biocompatibility, excellent photostability and low toxicity of the N-GQDs. ${ }^{22}$ From the view of application, the as-prepared N-GQDs showing yellow fluorescence were further employed as possible fluorescence probes for detecting $\mathrm{Fe}^{3+}$, considering that (a) the abnormal amount of ferric ion may cause some diseases like anemia and Parkinson's disease for human; (b) the effective chelation of ferric ion with nitrogen- and oxygen-containing functional groups of the N-GQD. Fig. 7A displays fluorescence spectra of NGQDs solution containing different concentration of $\mathrm{Fe}^{3+}$. Significantly, with the increase of $\mathrm{Fe}^{3+}$, the fluorescence intensity was linearly quenched in the concentration of 0.5 to $40 \mu \mathrm{M}$ (Fig. 7B). The linear equation is $F / F_{0}=1.00024-0.02166 \times C_{\mathrm{Fe}^{3+}}$ ( $R=0.997)$, where $F$ and $F_{0}$ was the fluorescent intensity of GQDs solution with and without $\mathrm{Fe}^{3+}$, respectively. The experimental result demonstrated that the obtained N-GQDs with yellow fluorescence might have potential for the detection of ferric ion in aqueous medium.

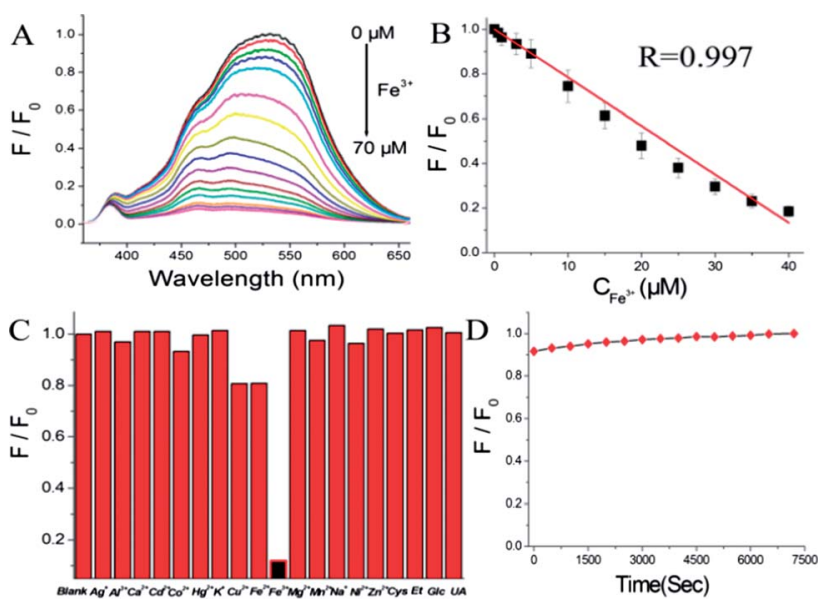

Fig. 7 (A) Fluorescence spectra of the N-GQDs with different concentrations of $\mathrm{Fe}^{3+}$ (from top to bottom: 0, 0.5, 1, 3, 5, 10, 15, 20, $25,30,35,40,45,50,55,60,65,70 \mu \mathrm{M})$. (B) Calibration curve for $\mathrm{Fe}^{3+}$ detection. $F$ and $F_{0}$ are the fluorescence intensities of the N-GQDs with and without $\mathrm{Fe}^{3+}$, respectively $\left(\lambda_{\mathrm{ex}}=340 \mathrm{~nm}\right)$. (C) Selectivity of $\mathrm{N}$ GQDs for AA and other substances. From left to right: blank, $\mathrm{Ag}^{+}, \mathrm{Al}^{3+}$, $\mathrm{Ca}^{2+}, \mathrm{Cd}^{2+}, \mathrm{Co}^{2+}, \mathrm{Hg}^{2+}, \mathrm{K}^{+}, \mathrm{Cu}^{2+}, \mathrm{Fe}^{2+}, \mathrm{Fe}^{3+}, \mathrm{Mg}^{2+}, \mathrm{Mn}^{2+}, \mathrm{Na}^{+}, \mathrm{Ni}^{2+}$, $\mathrm{Zn}^{2+}, \mathrm{Cys}, \mathrm{Et}, \mathrm{Glc}$ and UA. (D) A time-dependent photoluminescence spectrum of N-GQDs. Experimental condition: $\lambda_{\mathrm{ex}}=340 \mathrm{~nm}$; Xe lamp of $150 \mathrm{~W}$. 
A

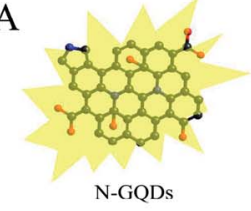

Strong Fluorescence

.

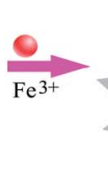

$\mathrm{Fe}^{3+} \quad \mathrm{Fe}^{2+}$

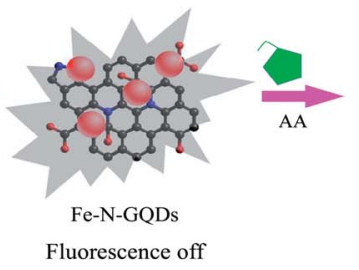

Fluorescence off

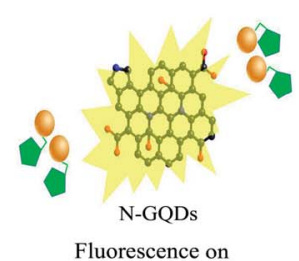

Fluorescence on

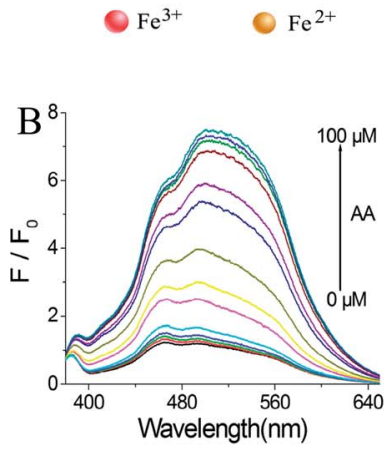

AA
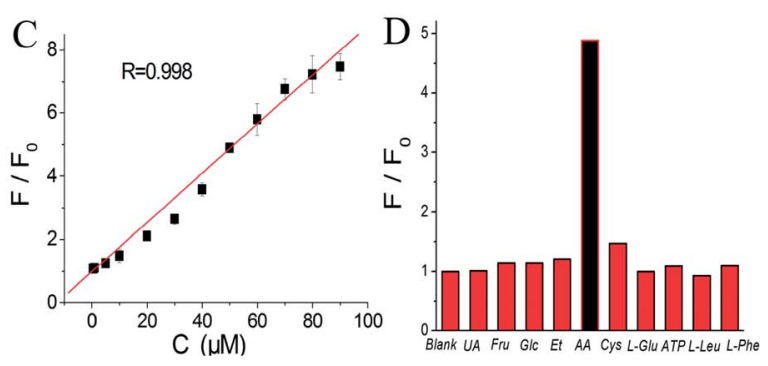

Fig. 8 (A) Schematic representation of the possible detection process for AA via using N-GQDs probes. (B) Fluorescence spectra of N-GQDs solution with $50 \mu \mathrm{M}$ ferric ion and different concentrations of AA (from bottom to top: $0,0.5,1,5,10,20,30,40,50,60,70,80,90,100 \mu \mathrm{M}$ ). (C) F/ $F_{0}$ versus the concentration of AA. $F_{0}$ and $F$ is fluorescence intensity in the absence and presence of AA, respectively. (D) Selectivity of the developed sensor for AA and other biologically relevant species including UA, Fru, Glc, Et, AA, Cys, L-Glu, ATP, L-Leu, L-Phe. Fo and F are fluorescence intensities in the absence and presence of biomolecules, respectively.

To examine the selectivity of the N-GQDs for $\mathrm{Fe}^{3+}$ detection, the environmentally relevant metal ions including $\mathrm{Pb}^{2+}, \mathrm{Al}^{3+}$, $\mathrm{Ni}^{2+}, \mathrm{Hg}^{2+}, \mathrm{Cu}^{2+}, \mathrm{Co}^{2+}, \mathrm{Fe}^{2+}, \mathrm{Na}^{+}, \mathrm{K}^{+}, \mathrm{Cd}^{2+}, \mathrm{Ag}^{+}, \mathrm{Zn}^{2+}$ and $\mathrm{Mn}^{2+}$ were examined under the same concentration of $50 \mu \mathrm{M}$. Besides, $\mathrm{Ca}^{2+}$ of $130 \mu \mathrm{M}$ and $\mathrm{Mg}^{2+}$ of $370 \mu \mathrm{M}$ were employed as interferential ions too, due to their high content in reality. Also, some biomolecules such as glucose (Glc, $4 \mathrm{mM}$ ), ethanol (Et, $10 \mathrm{mM}$ ), cysteine (Cys, $100 \mu \mathrm{M})$ and uric acid (UA, $100 \mu \mathrm{M})$ in the blood plasma $^{41}$ were investigated for the interferential study (see Fig. 7C). It was found that the fluorescence intensity of N-GQDs decrease remarkably about $88 \%$ in the presence of $50 \mu \mathrm{M} \mathrm{Fe}^{3+}$ while other metal ions and those biomolecules exhibited negligible fluorescence fluctuations at normal physiological concentration. These experimental results suggested N-GQDs possess higher selectivity towards ferric ion in aqueous solution. Its high selectivity may be due to the specific coordination of ferric ions with N/O functional groups on the N-GQDs, which may form a $\mathrm{Fe}^{3+}-\mathrm{N}-\mathrm{GQD}$ complex, and thus result in a strong fluorescence quenching. ${ }^{10}$ Furthermore, the photostability of N-GQDs was investigated and exhibited in Fig. 7D. Significantly, fluorescence intensity of the N-GQDs increased merely $9 \%$ after a continuous irradiation of two hours with a Xe lamp $(150 \mathrm{~W})$, demonstrating a relatively high photostability of this quantum dot.

The analytical application of N-GQDs was carried out by employing the N-GQDs as fluorescence probes for the detection of ferric ion in tap water samples. The detection results were displayed in Table S1. $\dagger$ Significantly, the recoveries of three samples are $93.1-107.3 \%$ and corresponding RSD is $3.2-5.7 \%$, demonstrating the applicability and reliability of $\mathrm{Fe}^{3+}$ detection by the N-GQDs fluorescent sensor.

3.3.3 Determination of ascorbic acid based on $\mathrm{Fe}^{3+}-\mathrm{N}$ GQDs. Recently, some significant research results

Table 1 Performance comparison of the proposed method with other previous approaches in AA detection

\begin{tabular}{|c|c|c|c|c|}
\hline Method & Technique in detail & $\begin{array}{l}\text { Detection limit } \\
(\mu \mathrm{M})\end{array}$ & $\begin{array}{l}\text { Linear range } \\
(\mu \mathrm{M})\end{array}$ & Ref. \\
\hline Colorimetry & Mesoporous silica-coated gold nanorods & 0.049 & $0.1-2.5$ & 25 \\
\hline Colorimetry & $\mathrm{Fe}_{3} \mathrm{O}_{4} /$ nitrogen-doped carbon hybrid nanofibers & 0.04 & $0-50$ & 43 \\
\hline Electrochemistry & Iridium oxide nanofibers modified glassy carbon electrode & 0.4 & $1-1000$ & 44 \\
\hline Electrochemistry & Mesoporous silica/polyaniline/gold nanoparticles modified carbon paste electrode & 0.97 & $5-13300$ & 27 \\
\hline Fluorescence & GQDs & 0.32 & $1.11-300$ & 2 \\
\hline Fluorescence & CdTe QDs@silica nanobeads & 1.25 & $3.33-400$ & 45 \\
\hline Fluorescence & Au nanoclusters & 0.022 & $0.1-10$ & 46 \\
\hline Fluorescence & Silver nanoparticles & 0.1 & $4.1-100$ & 23 \\
\hline Fluorescence & CdS QDs & 0.002 & $0.06-0.3$ & 47 \\
\hline Fluorescence & CQDs/Au nanoclusters nanohybrid & 0.105 & $0.15-15$ & 48 \\
\hline Fluorescence & N-GQDs & 0.08 & $0.5-90$ & This \\
\hline
\end{tabular}


demonstrated the quenched fluorescence of GQDs by metal ions can be effectively recovered by specific biomolecules, thus constructing the biomolecule sensors based on the on-off-on fluorescence response.,42 For instance, Kang's group found that the fluorescence quenching of GQDs occurred with the addition of $\mathrm{Cu}^{2+}$ due to the reaction of GQDs with $\mathrm{Cu}^{2+} \cdot{ }^{42}$ Subsequently, the quenched fluorescence was recovered by destroying the coordinate between GQDs and $\mathrm{Cu}^{2+}$ via the addition of an ascorbic acid (AA) that could reduce effectively cupric ion to cuprous ion as a strong reducing agent. So, a simple and sensitive AA sensor was successfully accomplished by them via using above on-off-on fluorescence response strategy. Next, we want to indicate the previous $\mathrm{Fe}^{3+}-\mathrm{N}-\mathrm{GQD}$ complex can be applied to establish a label-free and off-to-on fluorescence sensing of AA. As shown in schematic diagram of Fig. 8A, the fluorescence of the $\mathrm{Fe}^{3+}-\mathrm{N}-\mathrm{GQDS}$ system was turned "on" because the disaggregation of the $\mathrm{Fe}^{3+}-\mathrm{N}-\mathrm{GQD}$ complex was achieved via the reduction of $\mathrm{Fe}^{3+}$ to $\mathrm{Fe}^{2+}$ with the aid of reductive ascorbic acid. Based on the restored fluorescence of N-GQDs, AA may be determined selectively and simply. Fig. 8B shows the fluorescence spectra of the $\mathrm{Fe}^{3+}-\mathrm{N}-\mathrm{GQDS}$ mixture with the varied AA concentrations ranging from 0 to $100 \mu \mathrm{M}$. Noteworthily, the restoring fluorescence of $\mathrm{Fe}^{3+}-\mathrm{N}-\mathrm{GQDS}$ increases linearly with the increment of AA in the range of 0.5 to $90 \mu \mathrm{M}$. The linear regression equations are defined as $F / F_{0}=$ $1+0.07755 \times C_{\mathrm{AA}}(R=0.998$, Fig. 8C). And the detection limit for this detection system is estimated to be $0.08 \mu \mathrm{M}$ at a signalto-noise ratio of 3 .

Selectivity of fluorescence sensor is another important indicator for evaluating its sensing performance. Therefore, in this work, the influence of biologically relevant reactive species such as uric acid, fructose, glucose, ethanol, cysteine, L-glutamic acid (L-Glu), adenosine triphosphate (ATP), L-phenylalanine (L-Phe), L-Leucine (L-Leu) was studied at the same experimental condition. As indicated in Fig. 8D, these relevant interfering compounds did not cause any obvious interference, clearly demonstrating that the N-GQDs-based sensing system possesses high selectivity towards AA.

To indicate the reliability of this developed sensor in AA detection, this sensor was employed to detection of AA in blood plasma of fish. Table $\mathrm{S} 2 \dagger$ exhibits a satisfactory recovery (95.3-106.2\%) and a low RSD (1.5-4.8\%), suggesting the reliability of this fluorescence sensor in ascorbic acid determination. Furthermore, a comparison of the performances of this NGQDs sensor with other relevant sensors was presented in Table 1. It could be observed that this developed fluorescence sensor showed wider linear range than those of Au nanoclusters, ${ }^{46} \mathrm{CdS}$ $\mathrm{QDs}^{47}$ CQDs/Au nanoclusters nanohybrid ${ }^{48}$ fluorescence sensors and some colorimetry AA sensors. ${ }^{25,43}$ Meanwhile, it also exhibited lower detection limit compared with GQDs, ${ }^{2} \mathrm{CdTe}$ QDs@silica nanobeads, ${ }^{45}$ silver nanoparticles ${ }^{23}$ fluorescence sensors and some electrochemistry AA sensors. ${ }^{27,44}$

\section{Conclusions}

To sum up, a novel N-GQD with controlled size have been firstly achieved by steaming $\mathrm{N}$-doped graphene layers in the confined nanospace of ordered mesoporous SBA-15 with an acid vapour. The present nanospace-confined synthesis of N-GQDs is lowcost and eco-friendly based on the reusability of SBA-15 template and liquid $\mathrm{HNO}_{3}$ as well as avoidable timeconsuming separation in terms of a self-designed glass steamer. The obtained N-GQDs are well-dispersed and exhibit yellow coloured fluorescence. And their fluorescence could be selectively quenched by ferric ion and subsequently restored with the addition of AA, exhibiting an on-off-on fluorescence response. As an application example, the as-prepared N-GQDs with high photostability and low toxicity were employed as fluorescence probes to determine both $\mathrm{Fe}^{3+}$ and $\mathrm{AA}$ with important biological role, exhibiting high selectivity, wide linear range and satisfactory recovery. Furthermore, the application of the N-doped graphene quantum dots with controllable preparation, low-cost and facile separation may be broadened in anticancer therapy, bioimaging, energy storage, drug delivery and so on.

\section{Conflicts of interest}

There are no conflicts to declare.

\section{Acknowledgements}

The authors acknowledge financial support from the project of Hebei Province Natural and Scientific Foundation (B2017101022, B2017101018), the project of Chengde Science and Technology Bureau (201606A070, 201606A069), and the young foundation project of Hebei Province Educational Bureau (QN2017408).

\section{Notes and references}

1 Z. P. Zhang, J. Zhang, N. Chen and L. T. Qu, Energy Environ. Sci., 2012, 5, 8869-8890.

2 H. Liu, W. D. Na, Z. P. Liu, X. Q. Chen and X. G. Su, Biosens. Bioelectron., 2017, 92, 229-233.

3 D. Iannazzo, I. Ziccarelli and A. Pistone, J. Mater. Chem. B, 2017, 5, 6471-6489.

4 C. Cheng, S. Li, A. Thomas, N. A. Kotov and R. Haag, Chem. Rev., 2017, 117, 1826-1914.

5 S. Benitez-Martinez and M. Valcarcel, TrAC, Trends Anal. Chem., 2015, 72, 93-113.

6 L. Li, G. Wu, G. Yang, J. Peng, J. Zhao and J. J. Zhu, Nanoscale, 2013, 5, 4015-4039.

7 S. J. Jeon, T. W. Kang, J. M. Ju, M. J. Kim, J. H. Park, F. Raza, J. Han, H. R. Lee and J. H. Kim, Adv. Funct. Mater., 2016, 26, 8211-8219.

8 B. J. Moon, D. Jang, Y. Yi, H. Lee, S. J. Kim, Y. Oh, S. H. Lee, M. Park, S. Lee and S. Bae, Nano Energy, 2017, 34, 36-46.

9 Y. Li, Y. Zhao, H. Cheng, Y. Hu, G. Shi, L. Dai and L. Qu, J. Am. Chem. Soc., 2012, 134, 15-18.

$10 \mathrm{~J} . \mathrm{Ju}$ and W. Chen, Biosens. Bioelectron., 2014, 58, 219-225.

11 X. T. Zheng, A. Ananthanarayanan, K. Q. Luo and P. Chen, Small, 2015, 11, 1620-1636. 
12 C. Zhu, S. Yang, G. Wang, R. Mo, P. He, J. Sun, Z. Di, N. Yuan, J. Ding, G. Ding and X. Xie, J. Mater. Chem. C, 2015, 3, 88108816.

13 Y. Y. Yin, Q. Liu, D. Jiang, X. J. Du, J. Qian, H. P. Mao and K. Wang, Carbon, 2016, 96, 1157-1165.

14 Q. Li, S. Zhang, L. Dai and L. S. Li, J. Am. Chem. Soc., 2012, 134, 18932-18935.

15 C. Hu, Y. Liu, Y. Yang, J. Cui, Z. Huang, Y. Wang, L. Yang, H. Wang, Y. Xiao and J. H. Rong, J. Mater. Chem. B, 2013, 1, 39-42.

16 Y. Liu and P. Wu, ACS Appl. Mater. Interfaces, 2013, 5, 33623369.

17 M. Bacon, S. J. Bradley and T. Nann, Part. Part. Syst. Charact., 2014, 31, 415-428.

18 L. Q. Song, J. J. Shi, J. Lu and C. Lu, Chem. Sci., 2015, 6, 48464850 .

19 H. B. Xu, S. H. Zhou, L. L. Xiao, S. Z. Li, T. Song, Y. Wang and Q. H. Yuan, Carbon, 2015, 87, 215-225.

20 S. K. Sahoo, D. Sharma, R. K. Bera, G. Crisponi and J. F. Callan, Chem. Soc. Rev., 2012, 41, 7195-7227.

21 J. S. A. Devi, S. Salini, A. H. Anulekshmi, G. L. Praveen and G. Sony, Sens. Actuators, B, 2017, 246, 943-951.

22 S. H. Zhou, H. B. Xu, W. Gan and Q. H. Yuan, RSC Adv., 2016, 6, 110775-110788.

23 H. W. Park, S. M. Alam, S. H. Lee, M. M. Karim, S. M. Wabaidur, M. Kang and J. H. Choi, Luminescence, 2009, 24, 367-371.

24 J. J. Li, X. F. Wang, D. Q. Huo, C. J. Hou, H. B. Fa, M. Yang and L. Zhang, Sens. Actuators, B, 2017, 242, 1265-1271.

25 G. Q. Wang, Z. P. Chen and L. X. Chen, Nanoscale, 2011, 3, 1756-1759.

26 H. Obata and C. M. G. van den Berg, Anal. Chem., 2001, 73, 2522-2528.

27 S. C. Hsu, H. T. Cheng, P. X. Wu, C. J. Weng, K. S. Santiago and J. M. Yeh, Electrochim. Acta, 2017, 238, 246-256.

28 M. G. Gioia, P. Andreatta, S. Boschetti and R. Gatti, J. Pharm. Biomed. Anal., 2008, 48, 331-339.

29 L. L. Feng, Y. X. Wu, D. L. Zhang, X. X. Hu, J. Zhang, P. Wang, Z. L. Song, X. B. Zhang and W. H. Tan, Anal. Chem., 2017, 89, 4077-4084.
30 D. Y. Zhao, J. L. Feng, Q. S. Huo, N. Melosh, G. H. Fredrickson, B. F. Chmelka and G. D. Stucky, Science, 1998, 279, 548-552.

31 S. S. Kim, D. K. Lee, J. Shah and T. J. Pinnavaia, Chem. Commun., 2003, 12, 1436-1437.

32 A. H. Lu, W. C. Li, W. Schmidt, W. Kiefer and F. Schuth, Carbon, 2004, 42, 2939-2948.

33 S. Jarnbhrunkar, M. H. Yu, J. Yang, J. Zhang, A. Shrotri, L. Endo-Munoz, J. Moreau, G. Q. Lu and C. Z. Yu, J. Am. Chem. Soc., 2013, 135, 8444-8447.

34 Q. Liu, B. Guo, Z. Rao, B. Zhang and J. R. Gong, Nano Lett., 2013, 13, 2436-2441.

35 Y. Li, Y. Hu, Y. Zhao, G. Q. Shi, L. E. Deng, Y. B. Hou and L. T. Qu, Adv. Mater., 2011, 23, 776-780.

36 Y. Dong, H. Pang, S. Ren, C. Chen, Y. Chi and T. Yu, Carbon, 2013, 64, 245-251.

37 P. Guo, F. Xiao, Q. Liu, H. Liu, Y. Guo, J. R. Gong, S. Wang and Y. Liu, Sci. Rep., 2013, 3, 3499.

38 L. B. Tang, R. B. Ji, X. M. Li, K. S. Teng and S. P. Lau, J. Mater. Chem. C, 2013, 1, 4908-4915.

39 Y. Dong, C. Chen, X. Zheng, L. Gao, Z. Cui, H. Yang, C. Guo, Y. Chi and C. M. Li, J. Mater. Chem., 2012, 22, 8764-8766.

40 V. Gupta, N. Chaudhary, R. Srivastava, G. D. Sharma, R. Bhardwaj and S. Chand, J. Am. Chem. Soc., 2011, 133, 9960-9963.

41 W. Wang, L. L. Zhang, S. F. Tong, X. Li and W. B. Song, Biosens. Bioelectron., 2009, 25, 708-714.

42 J. J. Liu, Z. T. Chen, D. S. Tang, Y. B. Wang, L. T. Kang and J. N. Yao, Sens. Actuators, B, 2015, 212, 214-219.

43 Y. Z. Jiang, N. Song, C. Wang, N. Pinna and X. F. Lu, J. Mater. Chem. B, 2017, 5, 5499-5505.

44 S. J. Kim, Y. L. Kim, A. Yu, J. Lee, S. C. Lee, C. Lee, M. H. Kim and Y. Lee, Sens. Actuators, B, 2014, 196, 480-488.

45 Q. Ma, Y. Li, Z. H. Lin, G. C. Tang and X. G. Su, Nanoscale, 2013, 5, 9726-9731.

46 H. J. Meng, D. Q. Yang, Y. F. Tu and J. L. Yan, Talanta, 2017, 165, 346-350.

47 M. Ganiga and J. Cyriac, Anal. Bioanal. Chem., 2016, 408, 3699-3706.

48 W. J. Niu, D. Shan, R. H. Zhu, S. Y. Deng, S. Cosnier and X. J. Zhang, Carbon, 2016, 96, 1034-1042. 